\title{
A Rigorous Evaluation of Methoxyflurane is Needed: Comment on "Methoxyflurane Versus Standard of Care for Acute Trauma-Related Pain in the Emergency Setting: Protocol for a Randomised, Controlled Study in Italy (MEDITA)"
}

\author{
Emmanuel Montassier (D) - Yonathan Freund
}

Received: December 31, 2018 / Published online: March 30, 2019

(c) The Author(s) 2019

Keywords: Emergency department; Methoxyflurane; Non opioid analgesic; Opiates; Pain; Pain Management

We have read with careful attention the article, "Methoxyflurane Versus Standard of Care for Acute Trauma-Related Pain in the Emergency Setting: Protocol for a Randomised, Controlled Study in Italy" by Fabbri et al. [1]. The authors present MEDITA (Methoxyflurane in Emergency Department in ITAly), a Phase IIIb, prospective, randomised, active-controlled, parallel-group, open-label, multicentre trial. We agree with the authors that there is a need for better evidence for the use of methoxyflurane in pain management in the emergency department. Low-dose

Enhanced Digital Features To view enhanced digital features for this article go to https://doi.org/10.6084/ m9.figshare.7808753.

\section{E. Montassier ( $\square)$}

Department of Emergency Medicine, CHU Nantes, Nantes, France

e-mail: emmanuelmontassier@hotmail.com

\section{E. Montassier}

MiHAR Lab, Université de Nantes, 44000 Nantes, France

\section{Y. Freund}

Sorbonne Université, Paris, France

Y. Freund

Emergency Department, Hôpital Pitié-Salpêtrière, Paris, France methoxyflurane was approved based on the STOP! trial, which compared methoxyflurane only to placebo in young patients with acute trauma pain [2]. Despite a total absence of trials comparing methoxyflurane to an alternative analgesic available in the emergency department, huge efforts are made to introduce methoxyflurane to European emergency physicians, seen as a "global market" as reported in an online promotional video [3]. Indeed, they consider that methoxyflurane "can fit a very significant market need in terms of getting people out of pain, without them having to take a narcotic on board".

We noticed that the authors will include patients with moderate pain (Numeric Rating Scale 4-6), and that in these patients, guidelines recommend an oral non opioid analgesic that can be given as soon as in the triage room [4]. Whilst the authors argue that the cost of a morphine treatment is high, we wonder if the authors will include in their analysis the cost and time of preparation and education of the patient for the use of the inhaler, and will compare this to the very cheap and straightforward administration of a pill. A cost-effectiveness analysis does not seem to be planned.

We also question the primary endpoint pain assessment at $10 \mathrm{~min}$. The vast majority of the studies that evaluated pain management in the emergency department had a primary outcome at $30 \mathrm{~min}$, as reported in the evidence-based 
review from Sin et al. [5]. Thus, the added value of satisfactory analgesia at $10 \mathrm{~min}$ versus $30 \mathrm{~min}$ is unclear, and may not be seen as clinically relevant. This highly question the long term effect of methoxyflurane and the need for other antalgic treatment after the single dose of methoxyflurane received.

Finally, in the era of global warming, and following the Katowice Climate Change Conference (24th session of the Conference of the Parties), we believe that we cannot promote a treatment that cause such amount of waste, as the hand-held inhaler must be throw out after usage. Emergency physicians must take an active part in protecting our planet and prescribe other more environment-friendly medications for pain management.

For all these reasons, we strongly believe that we need independent trials if we want to avoid another future medical reversal [6]. Two trials have been recently funded by the French ministry of health [7].

\section{ACKNOWLEDGEMENTS}

Funding. No funding or sponsorship was received for this study or publication of this article.

Authorship. All named authors meet the International Committee of Medical Journal Editors (ICMJE) criteria for authorship for this article, take responsibility for the integrity of the work as a whole, and have given their approval for this version to be published.

Disclosures. Emmanuel Montassier and Yonathan Freund have nothing to disclose.

Compliance with Ethics Guidelines. This article is based on previously conducted studies and does not contain any studies with human participants or animals performed by any of the authors.

Peer Review. Please note, contrary to the journal's standard single-blind peer review process, as a letter this article underwent review by a member of the journal's Editorial Board.

Open Access. This article is distributed under the terms of the Creative Commons Attribution-NonCommercial 4.0 International License (http://creativecommons.org/licenses/ by-nc/4.0/), which permits any noncommercial use, distribution, and reproduction in any medium, provided you give appropriate credit to the original author(s) and the source, provide a link to the Creative Commons license, and indicate if changes were made.

\section{REFERENCES}

1. Fabbri A, Carpinteri G, Ruggiano G, et al. Methoxyflurane Versus Standard of Care for Acute TraumaRelated Pain in the Emergency Setting: Protocol for a Randomised, Controlled Study in Italy (MEDITA). Adv Ther. 2018. https://doi.org/10.1007/s12325-0180830-x.

2. Coffey F, Wright J, Hartshorn S, et al. STOP!: a randomised, double-blind, placebo-controlled study of the efficacy and safety of methoxyflurane for the treatment of acute pain. Emerg Med J. 2014;31:613-8.

3. https://www.youtube.com/watch?v=I8oZ5q8UHOI. Accessed 22 Dec 2018.

4. The College of Emergency Medicine. Management of pain in adults. 2014. https://www.rcem.ac.uk/docs/ College\%20Guidelines/5w.\%20Management\%20of\% 20Pain\%20in\%20Adults\%20(Revised\%20December\% 202014).pdf. Accessed 22 Dec 2018.

5. Sin B, Wai M, Tatunchak T, Motov SM. The use of intravenous acetaminophen for acute pain in the emergency department. Acad Emerg Med. 2016;23:543-53.

6. Prasad V, Cifu A. Medical reversal: why we must raise the bar before adopting new technologies. Yale J Biol Med. 2011;84(4):471-8.

7. https://solidarites-sante.gouv.fr/systeme-de-sante-etmedico-social/recherche-et-innovation/l-innovationet-la-recherche-clinique/appels-a-projets/programmesrecherche. Accessed 22 Dec 2018. 